lymphoblastic leukemia. J Pediatr 104:182-186

26. Chrousos GP, Poplack D, Brown T, O'Neill D, Schwade J, Bercu BB 1982 Effects of cranial radiation on hypothalamic-adenohypophyseal function: abnormal growth hormone secretory dynamics. J Clin Endocrinol Metab 54:1135-1139

27. Wigg DR, Murray RML, Koschel K 1982 Tolerance of the central nervous system to photon irradiation. Acta Radiol Oncol 21:49-60

28. Winter RJ, Green OC 1984 Irradiation induced growth hormone deficiency: blunted growth response and accelerated skeletal maturation to growth hormone therapy. J Pediatr 106:609-612

29. Prader A, Tanner JM, von Harnack GA 1963 Catch-up growth following illness or starvation. J Pediatr 62:646-659

30. Tanner JM 1963 The regulation of human growth. Child Dev 34:817-847

31. Mosier HD Jr, Jansons RA 1971 Allometry of body weight and tail length after head X-irradiation in rats. Growth 35:23-31

32. Winick M, Noble A 1966 Cellular response in rats during malnutrition at various ages. J Nutr 89:300-306

33. Williams JPG, Tanner JM, Hughes PCR 1974 Catch-up growth in female rats after growth retardation during the suckling period. Pediatr Res 8:149-156

34. Williams JPG, Tanner JM, Hughes PCR 1974 Catch-up growth in female rats after growth retardation during the suckling period. Comparison with males. Pediatr Res 8:157-162

35. Schjeide OA, Yamazaki J, Haack K, Ciminelli E, Clemente CD 1966 Biochemical and morphological aspects of radiation inhibition of myelin formation. Acta Radiol 5:185-203

36. Dearden LC, Mosier HD Jr, Thai C, Brundage M 1984 Effect of neonatal head $\mathrm{X}$-irradiation on growth of costal and tibial cartilage in rats: a histochemical and electron microscopic study. Basic Appl Histochem 28:117-136

\title{
Ovarian Hyperstimulation Syndrome in Preterm Infants
}

\author{
G. SEDIN, C. BERGQUIST, AND P. G. LINDGREN \\ The Departments of Paediatrics, Obstetrics and Gynaecology, and Diagnostic Radiology, University Hospital, \\ Uppsala, Sweden
}

\begin{abstract}
Estradiol-producing ovarian cysts were found in four very preterm females at a postconceptional age that slightly preceded the expected time of delivery. The serum concentration of estradiol was very high. In the first infant one cystic ovary was removed surgically. When cysts appeared in the other ovary, the girl was treated with medroxyprogesterone acetate. The serum concentration of estradiol then fell and the cysts disappeared. Medroxyprogesterone acetate treatment was given also to the second girl, who had a high and rising serum concentration of estradiol. In infants 3 and 4 the cysts disappeared and the serum estradiol normalized spontaneously. Measurements of serum concentrations of luteinizing hormone and folliclestimulating hormone before and after an iv injection of luteinizing hormone releasing hormone showed that preterm girls with early estradiol-producing ovarian cysts have a postpubertal type of response to luteinizing hormonereleasing hormone. When the test is repeated some months later they have a prepubertal type of response, which is normal for their age. (Pediatr Res 19: 548-551, 1985)
\end{abstract}

\section{Abbreviations}

FSH, follicle-stimulating hormone

LH, luteinizing hormone

LHRH, luteinizing hormone-releasing hormone

CPAP, continuous positive airway pressure

MPA, medroxyprogesterone acetate

HFPPV, high-frequency positive-pressure ventilation

Received July 13, 1984; accepted February 6, 1985

Reprint requests Dr. Gunnar Sedin, Department of Paediatrics, University Hospital, 75185 Uppsala, Sweden.

Supported by grants from the Swedish Medical Research Council (Project 19X04998 and $19 \mathrm{P}-6716)$
It has been demonstrated that the serum concentration of estrogens in full-term newborn infants decreases rapidly during the first hours after birth (1). A high serum level of estradiol is unlikely in newborn infants beyond the early neonatal period and few measurements have been made in early infancy. Recently high serum levels of FSH and LH have been found in preterm girls (2). Also, there have been few reports of estradiolproducing ovarian cysts in childhood; most reported cases have been associated with precocious puberty (3). As far as we know such ovarian cysts have not been reported during the neonatal period. Herein we report four cases of estradiol-producing ovarian cysts in preterm girls.

\section{MATERIALS AND METHODS}

Four preterm girls were found to have estradiol-producing ovarian cysts. All were born before the 30th wk of gestation. Symptoms, including swelling of the labia majora, appeared at a time corresponding to $1-4 \mathrm{wk}$ before the expected time of delivery, ie, 34-37 wk postconceptionally, or at 36-39 completed gestational weeks. A brief description of each case is given below. Maturity was assessed in all cases from external characteristics and on the basis of neurological criteria $(4,5)$. Immunoreactive FSH and LH in serum were assayed by a radioimmunosorbent technique with indirectly coupled antibodies (6). Immunoreactive estradiol in serum was measured by a radioimmunological method using an antiserum to an estradiol-6-oxime-bovine serum albumin conjugate (7). For the LHRH test informed consent was obtained from the parents. Ultrasonic examination was performed with a dynamic sector scanner (ATL Mark 300, $7.5 \mathrm{MHz}, \mathrm{ATL}$, Seattle, WA), and included both scanning for cysts and determination of uterine size. The latter was measured as the length of the uterus and this determination required that some urine was left in the bladder when the examination was made.

Infant 1 was born after 26 wk of gestation; birth weight was 
$852 \mathrm{~g}$ and birth length $34 \mathrm{~cm}$. The mother was healthy during this pregnancy. In the last 2 days before delivery she was treated with terbutaline because of preterm labor. The infant was delivered vaginally with a head presentation. After birth, the infant was in good condition with Apgar scores of 8 and 9 one and 5 min after birth. Physical examination revealed no respiratory disturbances. Assessment of maturity $(4,5)$ indicated a gestational age of 26 completed wk. During the neonatal period, the infant was treated with theophylline and CPAP because of recurrent apnea. Oral feeding was started early. The body weight was at its lowest $(675 \mathrm{~g}) 6$ days after birth and then gradually increased.

At $2 \frac{1 / 2}{2}$ months of age the infant's labia majora became edematous. Edema was also observed over the lower parts of the abdomen and on the legs. An ultrasonic examination of the abdomen and pelvis revealed a multilocular cystic tumor in the lower left part of the abdomen, with a maximal diameter of 40 $\mathrm{mm}$. The uterus measured $37 \times 17 \times 17 \mathrm{~mm}$, which was much larger than expected for her age. The serum concentration of estradiol was $5300 \mathrm{pmol} / \mathrm{liter}$, which is 10 times higher than that in the late follicular phase of the normal menstrual cycle of a fertile woman. A laparotomy was performed. The left ovary was found to be plum-sized, thin-walled, and cystic. The cystic left ovary was removed. The right ovary was of normal size and contained a small cyst, measuring a few millimetres in diameter. After the oophorectomy the serum concentration of estradiol fell to $440 \mathrm{pmol} /$ liter (Fig. 1) and the edema of the labia majora subsided. One week after surgery the edema increased again and the serum concentration of estradiol 11 days after surgery was $920 \mathrm{pmol} /$ liter. Ultrasonography now revealed cysts in the remaining right ovary, the largest one having a diameter of 20 $\mathrm{mm}$.

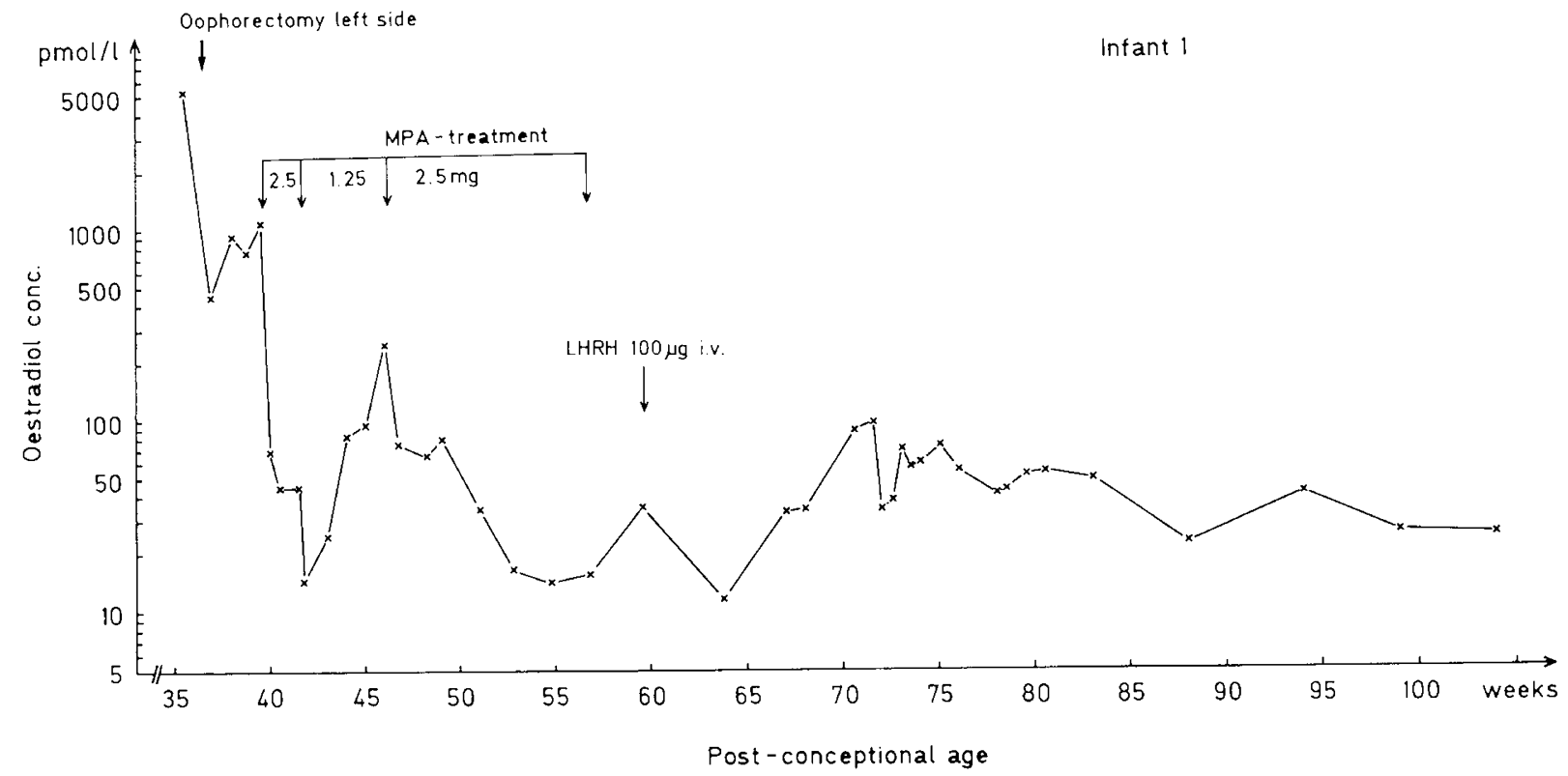

Fig. 1. Serum concentrations of estradiol in infant 1 in relation to postconceptional age. The period of treatment with MPA and the time of the LHRH test are indicated.

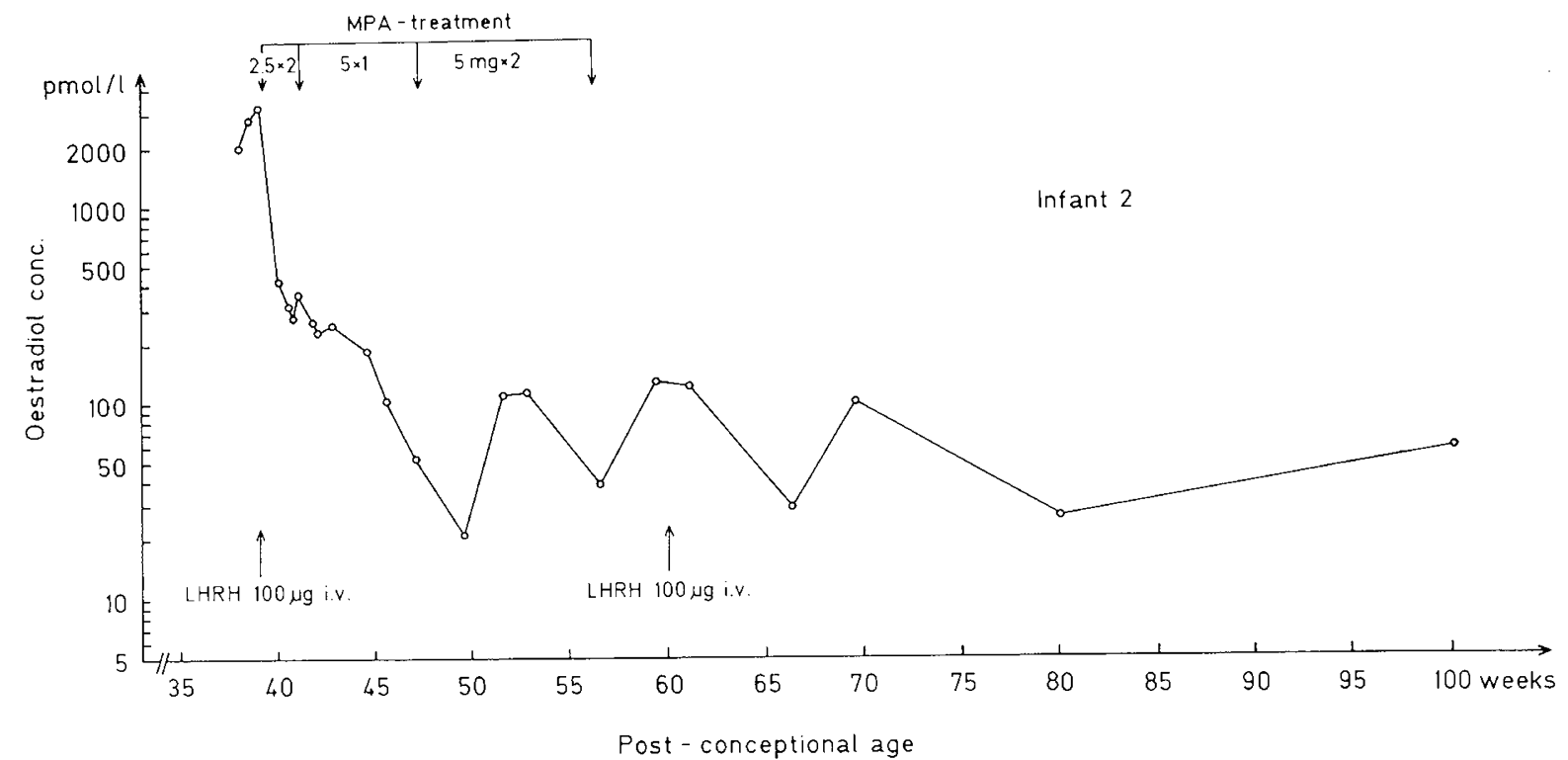

Fig. 2. Serum concentrations of estradiol in infant 2 in relation to postconceptional age. The period of treatment with MPA and the times of the LHRH tests are indicated. 
Histopathological examination of the excised left ovary showed multiple follicular cysts and a stroma with a possible increase in theca cells. There were no signs of malignancy. Considering that the ovary may have become cystic as a result of gonadotrophin hyperstimulation, MPA was given. Initially an oral dose of 2.5 $\mathrm{mg}$ daily was administered, later decreased to $1.25 \mathrm{mg}$ daily. Figure 1 shows the time course of the serum concentrations of estradiol. During treatment with MPA the serum concentration of estradiol fell and remained low. Repeated ultrasonography showed a disappearance of the ovarian cysts as the serum concentration of estradiol fell (8). Three weeks after discontinuation of MPA therapy, $100 \mu \mathrm{g}$ of LHRH were injected iv and the serum concentrations of FSH and LH were measured before and 45 min after the injection (see "Results").

Infant 2 was born after 28 wk gestation with a birth weight of $767 \mathrm{~g}$ and a birth length of $35 \mathrm{~cm}$. She was small for gestational age. Three weeks before delivery signs of intrauterine growth retardation were observed. When pathological cardiotocographic recordings were observed, the infant was delivered by cesarean section. After birth the infant was in good condition. Apgar scores were 7 and 9 one and $5 \mathrm{~min}$ after birth. The infant developed hyaline membrane disease and was treated with CPAP for 14 days, first because of the lung disease and later because of recurrent apnoea. She was also given theophylline.

At 11 wk of age edema was observed in the lower part of the abdominal wall and the labia majora. Ultrasonography of the abdomen revealed fluid-filled cavities diagnosed as ovarian cysts. The serum concentration of estradiol was $2000 \mathrm{pmol} / \mathrm{liter}$. During the following week two further estradiol determinations were 2800 and $3200 \mathrm{pmol} /$ liter. An LHRH test was also performed. Because of the ovarian cysts and the concurrently high and increasing serum concentrations of estradiol, treatment with MPA $5.0 \mathrm{mg}$ daily was instituted. The serum concentration of estradiol decreased but the ovarian cysts persisted and the MPA dose was increased to $10 \mathrm{mg}$ daily. Figure 2 illustrates the serum concentration of estradiol during the course of treatment. Three weeks after discontinuation of MPA therapy a further LHRH test was performed (see "Results").

Infant 3 was born after 28 wk gestation with a birth weight of $794 \mathrm{~g}$ and a length of $37 \mathrm{~cm}$. She was small for gestational age. The girl was in fair condition immediately after birth with Apgar scores of 6 and 6 . Because spontaneous breathing was insufficient, she was intubated and given HFPPV (9). She was on HFPPV for 26 days and was then treated with CPAP for almost a month because of recurrent apnea. She was also given theophylline.

At a postnatal age of $11 \mathrm{wk}$ a blood sample for determination of serum estradiol was taken because of slight swelling of the labia majora. In this infant a serum concentration of estradiol of $100 \mathrm{pmol} / \mathrm{liter}$ was found early after birth and at $11 \mathrm{wk}$ of age increased to $2000 \mathrm{pmol} /$ liter (Fig. 3). Repeated determinations showed decreasing levels. An LHRH test was performed. Ultrasonography of the abdomen revealed ovarian cysts on the left side with a maximal diameter of $9-10 \mathrm{~mm}$. Repeated assays of serum estradiol showed a gradual decrease in concentration and no MPA treatment was instituted. Ovarian cysts, especially on the left side, persisted during the following 8-9 wk. The result of the LHRH tests are presented in "Results".

Infant 4 was born after 24 wk of gestation with a birth weight of $625 \mathrm{~g}$ and a birth length of $32 \mathrm{~cm}$. She was in fair condition after birth, with Apgar scores of 6 and 8. Her spontaneous breathing was inadequate and she was given HFPPV almost immediately after birth. After 2 days she was extubated and put on nasal CPAP. Because of recurrent apnea, treatment with theophylline was instituted. She needed six further shorter periods on HFPPV before spontaneous breathing became stable. The treatment with CPAP was continued until she was 11 wk old. From the age of 6 wk she had edema and needed small intermittent doses of diuretics. Pulmonary radiography revealed low aeration at that time, but when the edema had disappared aeration was normal.

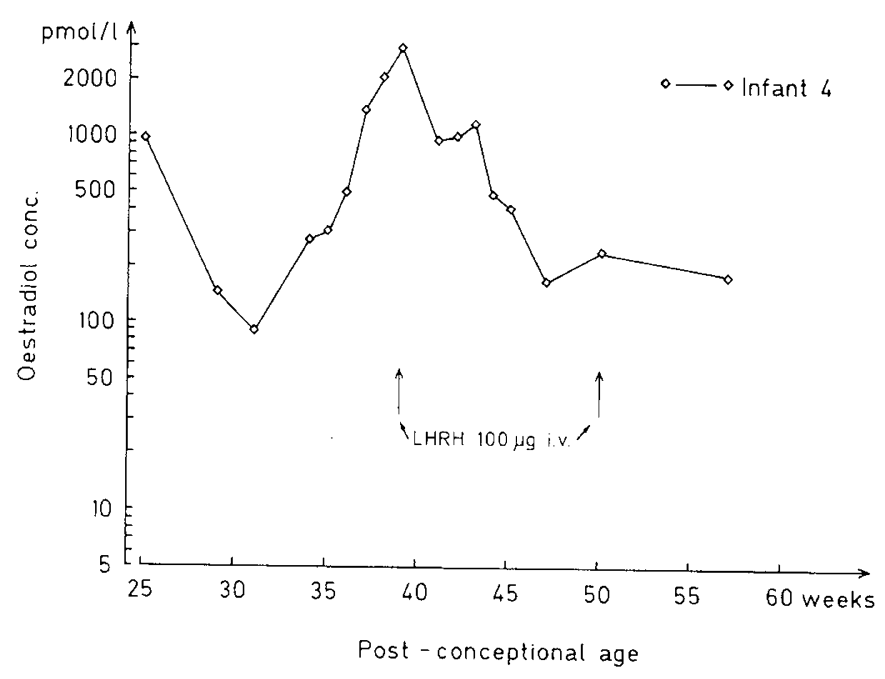

Fig. 4. Serum concentrations of estradiol in infant 4 in relation to postconceptional age. The times of LHRH tests are indicated.

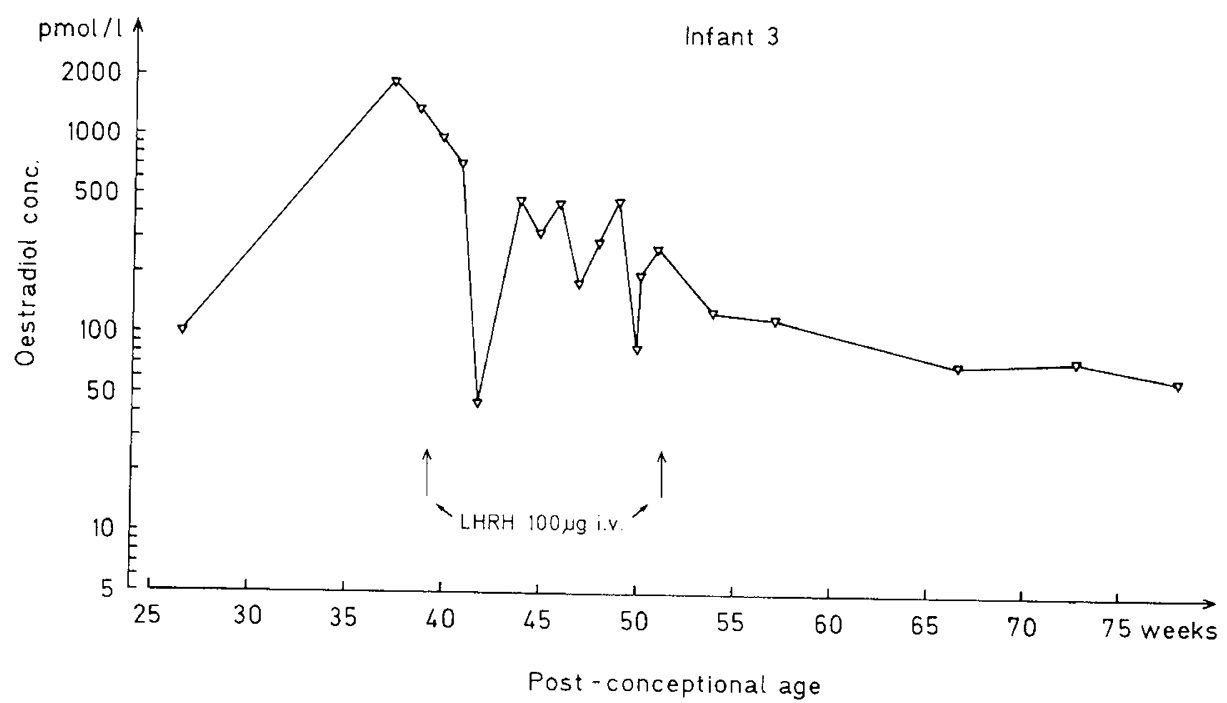

Fig. 3. Serum concentrations of estradiol in infant 3 in relation to postconceptional age. The times of LHRH tests are indicated. 


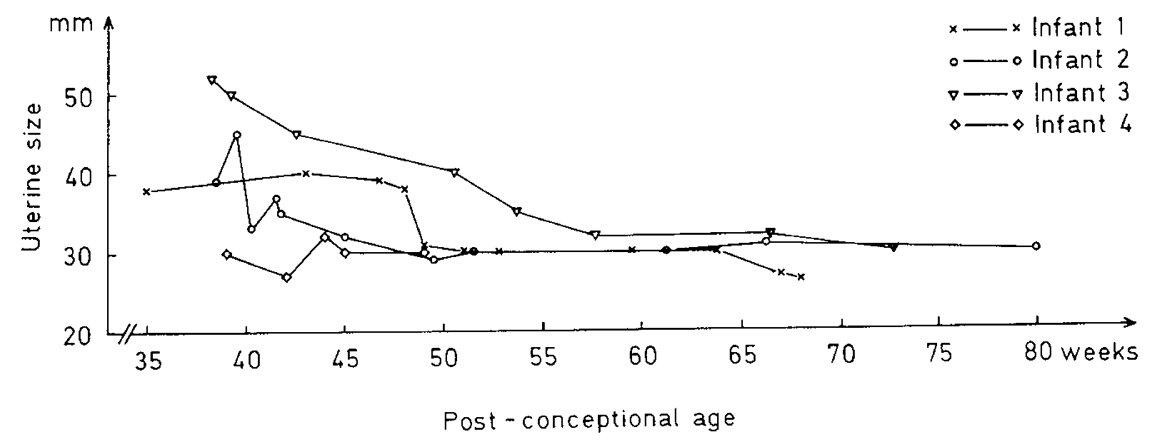

Fig. 5. Uterine size in relation to postconceptional age in infants 1-4.

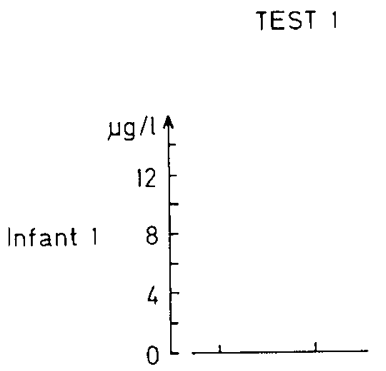

$$
-\mathrm{FSH}
$$

TEST 2
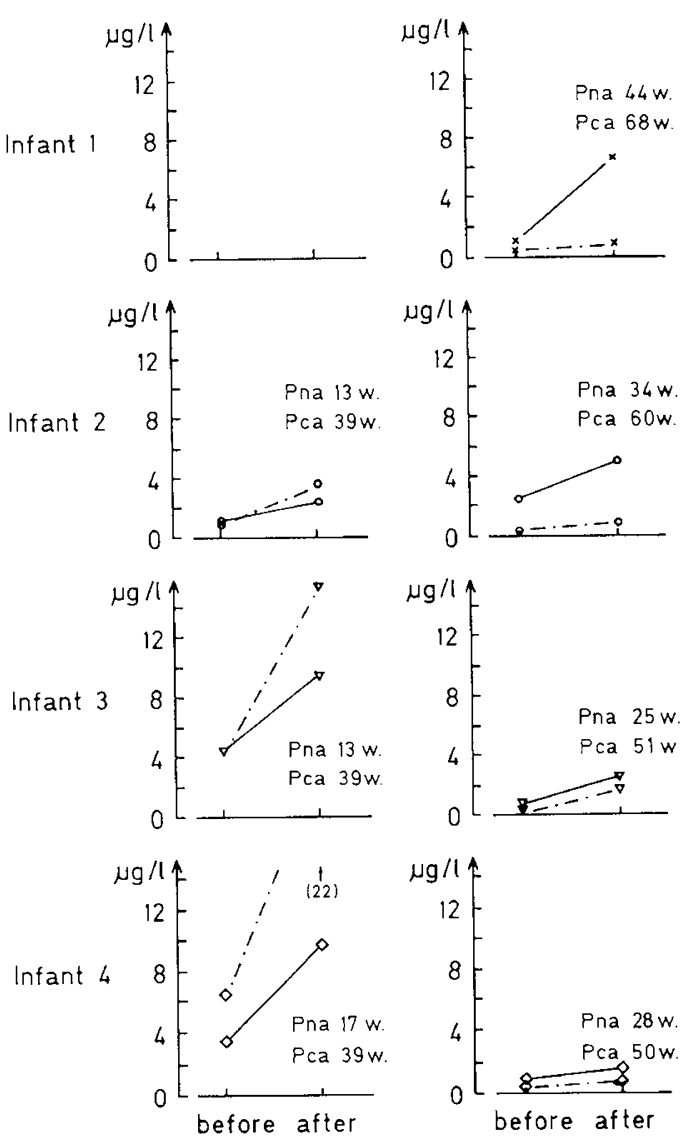

Fig. 6. Serum concentrations of FSH and $\mathrm{LH}$ before and $45 \mathrm{~min}$ after iv injection of $100 \mu \mathrm{g}$ of LHRH. The first test is to the left and the second test to the right.

The serum concentration of estradiol was $960 \mathrm{pmol} /$ liter at a postnatal age of $3 \mathrm{wk}$. At a postnatal age of $15 \mathrm{wk}$ a high value, $2100 \mathrm{pmol} /$ liter, was found (Fig. 4). Ultrasonography of the pelvis at that time revealed no cysts, but $2 \mathrm{wk}$ later ovarian cysts were observed bilaterally. The maximum diameter was 9-10 $\mathrm{mm}$. The serum concentration of estradiol fell gradually and on repeated ultrasonic examinations ovarian cysts could be seen for almost 3 months. After this period the serum concentration of estradiol had fallen to $230 \mathrm{pmol} / \mathrm{liter}$. The result of the LHRH tests are presented in "Results".

Neither gynecomastia nor vaginal blood discharge was observed in any of these four infants. In infants 1 and 2, who had obvious local edema, the plasma concentrations of albumin were normal.

\section{RESULTS}

The serum concentrations of estradiol are presented in Figures 1-4. In infant 1 ovarian cysts were seen for less than 2 wk after the start of MPA treatment. In infant 2, cysts were observed for almost $11 \mathrm{wk}$, and in infants 3 and 4 they were seen for 9 and $12 \mathrm{wk}$, respectively.

Uterine size, as determined ultrasonographically, is depicted in Figure 5. In infant 1, who had very high serum concentrations of estradiol; uterine size decreased rapidly on treatment with MPA. In infant 2 there was also a very rapid decrease in uterine size after the commencement of MPA. In infant 3, in whom a spontaneous decrease in serum estradiol occurred, the uterine size decreased much more slowly. In infant 4 the uterine size remained essentially unchanged during the entire study period.

The results of the LHRH tests in the four infants are presented in Figure 6. In infant 1 only one test was performed after discontinuation of MPA treatment, while in the other three infants one test was carried out at the time of diagnosis and another 2-4 months after the calculated time of delivery. As seen in Figure 6 , in the first test the increase in LH was much more marked than the increase in FSH, which is a postpubertal type of response to an injection of LHRH. In the second test the FSH response was stronger than the LH response in all infants and the preinjection serum concentration of $\mathrm{LH}$ was low. This is a normal prepubertal response.

All infants were in good condition when the ovarian cysts disappeared. Their growth was satisfactory and their development normal.

\section{DISCUSSION}

Herein we report four very preterm infants with estradiolproducing ovarian cysts. Estradiol-producing ovarian cysts cause swelling of the labia majora and sometimes edema in the lower parts of the abdominal wall. The uterine size is concomitantly increased. We found no previous reports of estradiol-producing ovarian cysts in preterm infants born before $30 \mathrm{wk}$ gestation.

Clements et al. (10) and Winter et al. (11) reported low levels of FSH and LH in amniotic fluid in late gestation and low levels of FSH and LH in cord sera at birth of full-term infants. Polhemus (12) observed increased follicular maturation and Bidlingmeier et al. (13) found elevated serum concentrations of estradiol in full-term infants after birth. Their observations were thus made in full-term infants, while our infants were very preterm.

From a developmental point of view our finding of extremely high levels of FSH and LH measured in very preterm girls at a postconceptional age corresponding to or slightly earlier than the calculated time of delivery, indicates marked stimulation of the ovaries after birth. Recently, Tapanainen et al. (2) found high serum concentrations of FSH and LH in premature infants born after $32 \mathrm{wk}$ of gestation. The present observations indicate that some very preterm girls develop ovarian cysts with high serum 
concentrations of estradiol. This may be a result of the high circulating levels of FSH and LH postnatally, which cause hyperstimulation of the ovaries. The withdrawal of placental steroids at birth probably results in activation of the hypothalamicpituitary-gonadal unit. In full-term newborn infants, low levels of sex steroids inhibit the hypothalamic-pituitary-gonadal unit as a result of high sensitivity in the negative feedback system (3). The negative feedback system may be too immature in preterm girls to respond to low levels of estradiol. The finding in the present study that preterm girls have a postpubertal type of response to iv injection of LHRH when first examined but have a normal prepubertal type of response some months later, suggests that normal maturation of the hypothalamic-pituitarygonadal system takes place in utero during late gestation in the presence of high levels of estrogen. The maturation process in preterm girls in the extrauterine environment occurs without the negative feedback of the placental steroids, resulting in high levels of gonadotrophins and as a consequence a tendency to develop "the ovarian hyperstimulation syndrome."

MPA inhibits release of gonadotrophins and thus prevents hyperstimulation of the ovaries. We do not recommend this treatment as a routine procedure in all cases of estradiol-producing ovarian cysts, but at the moment we see no alternative treatment in infants with very high estrogen evels $(\gg 2000 \mathrm{pmol} /$ liter).

Acknowledgments. The authors thank C. Ewald for taking the samples for determination of serum concentrations, L. Wide for analysing the blood samples, and B. Östmark for skillful laboratory assistance.

\section{REFERENCES}

1. Kenny FM, Angsusingha K, Stinson D, Hotchkiss J 1973 Unconjugated estrogens in the perinatal period. Pediatr Res 7:826-831

2. Tapanainen J, Koivisto M, Vihko R, Huhtaniemi I 1981 Enhanced activity of the pituitary-gonadal axis in premature infants. J Clin Endocrinol Metab $52: 235-238$

3. Grumbach MM, Kaplan SL 1974 Fetal pituitary hormones and the maturation of central nervous system regulation of the anterior pituitary function. In: Gluck L (ed) Modern Perinatal Medicine. Year Book Medical Publishers Chicago, pp 247-271

4. Dubowitz LMS, Dubowitz V, Goldberg C 1970 Clinical assessment of gestational age in the newborn infant. J Pediatr 77:1-10

5. Finnström O 1977 Studies on maturity in newborn infants. IX. Further observations on the use of external characteristics in estimating gestational age. Acta Paediatr Scand 66:601-604

6. Wide L, Nillius SJ, Gemzell C, Roos P 1973 Radio-immunosorbent assay of follicle stimulating hormone and luteinizing hormone in serum and urine from men and women. Acta Endocrinol [Suppl] (Copenh) 174:1-58

7. Hotchkiss J, Atkinsson LE, Knobil E 1971 Time course of serum estrogen and luteinizing hormone $(\mathrm{LH})$ concentrations during the menstrual cycle of the rhesus monkey. Endocrinology 89:177-183

8. Bergqvist C, Esscher T, Lindgren PG, Lundkvist K, Sedin G 1984 Cystic ovaries in a pre-term newborn infant. $Z$ Kinderchir 39:403-404

9. Sedin $G 1983$ Hochfrequente Ueberdruckbeatmung in der Neugeborenenintensivbehandlung. In: Pohlandt $F$ (ed) Pädiatrische Intensivmedizin, Vol V, INA 41. George Thieme Verlag, Stuttgart, pp 50-53

10. Clements JA, Reyes FI, Winter JSD, Faiman C 1976 Studies on human sexual development. III. Fetal pituitary and serum, and amniotic fluid concentrations of LH, CG, and FSH. J Clin Endocrinol Metab 42:9-19

11. Winter JDS, Hughes IA, Reyes FI, Faiman C 1976 Pituitary-gonadal relations in infancy: 2. Patterns of serum gonadal steroid concentrations in man from birth to two years of age. J Clin Endocrinol Metab 42:679-686

12. Polhemus DW 1953 Ovarian maturation and cyst formation in children. Pediatrics 11:588-594

13. Bidlingmeier F, Versmold H, Knorr D 1974 Plasma estrogens in newborns and infants. In: Forest MG, Bertrand J (eds) Endocrinologie Sexualle de la Periode Perinatale. Editions INSERM, Paris, 32:299-314

\title{
Alterations in Gas Exchange Associated with Lobar Atelectasis in Young Piglets
}

\author{
GREGORY J. REDDING, THOMAS A. STANDAERT, AND WILLIAM E. TRUOG \\ Department of Pediatrics, University of Washington School of Medicine, Seattle, Washington 98195
}

\begin{abstract}
Lobar atelectasis is common among infants and children with obstructive lung diseases. However, the effect of lobar collapse in the presence of diffuse lung disease on gas exchange in the pediatric age group has not been described. We developed an infant model of lobar atelectasis using piglets and tested the hypothesis that diffuse alveolar hypoxia increases shunt fraction $\left(\dot{Q}_{\mathrm{s}} / \dot{\mathrm{Q}}_{\mathrm{T}}\right)$ associated with lobar atelectasis by redirecting pulmonary blood from the well-ventilated portion of the lung into the collapsed region. Shunt fraction was determined using the multiple inert gas elimination technique. The proportion of pulmonary blood flow perfusing the left lower lobe was measured with microspheres. $\dot{\mathrm{Q}}_{\mathrm{s}} / \dot{\mathrm{Q}}_{\mathrm{T}}$ increased significantly but by a variable amount to an average value $( \pm \mathrm{SD})$ of 5.9
\end{abstract}

Received November 8, 1984; accepted February 6, 1985.

Reprint requests Dr. Gregory J. Redding, Department of Pediatrics, RD-20, Division of Neonatal and Respiratory Diseases, University of Washington, Seattle, WA 98195 .

Supported by NIH Grant HL19187 and MCH Grant 00955. $\mathbf{\pm} .2 \%$ following lobar collapse. The percentage of cardiac output perfusing the left lower lobe fell by an average of $70 \pm 17 \%$ in response to lobar collapse. When animals were ventilated with $12 \%$ oxygen, shunt fraction increased to $18.7 \pm 7.1 \%$ and blood flow to the collapsed left lower lobe increased from $9 \pm 3$ to $22 \pm 3 \%$ of cardiac output. Lobar atelectasis in conditions where diffuse alveolar hypoxia is present may be associated with a significantly greater intrapulmonary shunt than lobar atelectasis in children with otherwise normal lungs. (Pediatr Res 19: 552556,1985 )

\section{Abbreviations}

Ppa, pulmonary artery pressure

$\mathrm{PvO}_{2}$, mixed venous oxygen tension

$\mathrm{CO}$, cardiac output

TPR, total pulmonary resistance 